\title{
Use of office package of free software in high school of Santa Rosalía, BCS
}

\section{Uso de paquete ofimático de software libre en el instituto de Santa Rosalía, BCS}

\author{
MEZA-ARELLANO, Antonio †*, HERNÁNDEZ-VALENZUELA, Juan Carlos and \\ VILLAVICENCIO-LÓPEZ, José Ignacio \\ Instituto Tecnológico Superior de Mulegé
}

ID $1^{\text {st }}$ Author: Antonio, Meza-Arellano / ORC ID: 0000-0002-6553-8392, Researcher ID Thomson: P-6194-2018, CVU CONACYT ID: 404918

ID $1^{\text {st }}$ Coauthor: Juan Carlos, Hernández-Valenzuela / ORC ID: 0000-0003-3523-232, Researcher ID Thomson: P-43442018, CVU CONACYT ID: 278735

ID $2^{\text {nd }}$ Coauthor: José Ignacio, Villavicencio-López

DOI: $10.35429 / J S E M .2020 .20 .7 .17 .25$

Received January 15, 2020; Accepted June 21, 2020

\begin{abstract}
The present article shows the results of the study carried to the junior high schools of Santa Rosalía Baja California Sur, to identify the level of knowledge that the students and teachers have about the free office software package, where the result obtained was a high percentage of ignorance. It should be noted the great availability and acceptance shown by students and teachers towards this software package based on free software. To carry out this study, it was used the exploratory and descriptive methods, where the study sample was a total of 135 students and 44 teachers who replied the surveys and interviews, which were conducted in two stages: the first one, was carried out to know the level of knowledge the school community has about of office programs of free software; the second one, was done to know the level of acceptance of it.
\end{abstract}

Office automation software (Office suite), free software, basic education, programs, migration

\begin{abstract}
Resumen
El presente artículo muestra los resultados del estudio realizado a las escuelas secundarias de la localidad Santa Rosalía Baja California Sur, para identificar el índice de conocimientos que se tiene sobre la paquetería de ofimática de software libre, donde el resultado obtenido fue un alto porcentaje de desconocimiento. Cabe destacar la gran disponibilidad y aceptación que se mostró por parte de alumnos y docentes hacia esta paquetería basada en software libre. Para llevar a cabo dicho estudio, se utilizaron los métodos exploratorio y descriptivo donde la muestra de estudio fue de un total de 135 alumnos y 44 docentes, a quienes se les aplicaron las encuestas y entrevistas, las cuales fueron realizada en dos etapas: la primera etapa, se llevó a cabo para deducir el nivel de conocimiento que la comunidad escolar tiene respecto a los programas ofimáticos de software libre, mientras que la segunda, se hizo para conocer el índice de aceptación de esta misma.
\end{abstract}

Educación básica, Migración, Paquetería de ofimática (Suite de ofimática), software libre, programas

Citation: MEZA-ARELLANO, Antonio, HERNÁNDEZ-VALENZUELA, Juan Carlos and VILLAVICENCIO-LÓPEZ, José Ignacio. Use of office package of free software in high school of Santa Rosalía, BCS. Journal of Systems and Educational Management. 2020. 7-20: 17-25.

\footnotetext{
*Correspondence to Author (Email: antonio.meza@itesme.edu.mx)

$\dagger$ Researcher contributing as first Author.
} 


\section{Introduction}

The general purpose of this research is to investigate the level of knowledge of the free software office package in basic education for both students and teachers, obtaining as a result a high rate of ignorance of this teaching tool, regarding this it was shown great availability and enthusiasm from both parties to get to know it and learn how to use it, as they are aware that having this new alternative will help improve their performance.

Although it is true, the Secretary of Public Education (SEP), has set aside a capital for the purchase of office automation package licenses that are used in the laboratories that exist in the different schools, which is the reason for the investigation., it is noted that a low percentage of the study population believe that some free software office packages are aware, however, there is resistance to change. The benefit of free software is that it does not have a cost as such.

By adopting this package of free software office, both parties will benefit because in addition to knowing one that is the Microsoft Suite, it will help to have more than one alternative for the development of tasks such as their assignment.

Next, the methods used in the research process will be disclosed, analyzing the data obtained to specify the acceptance of this package based on free software, as well as the topics of: office automation package used in the secondary schools of the locality, being this Microsoft Office in its entirety, also the programs most used by students and teachers, both coinciding with the word processors, in the same way the places where they use the office package are shown, obtaining by the teachers with a higher percentage work, while students at school.

The aforementioned results in the proposal to migrate to LibreOffice as an alternative to the office software package currently used by Microsoft Office, this will bring benefits to the institutions that implement it, in addition to promoting the use of free software in teaching, which will generate students and teachers expand their knowledge and skills by contributing to their academic and professional development.

\section{Material and methods}

\section{Methodology}

The research method used was the descriptive and exploratory method, based on an analysis carried out at the secondary schools in the town, which are: Manuel F. Montoya, Colegio Salvatierra and Técnica 24, where two survey instruments and questionnaires were taken to carry carried out an analysis on the knowledge and use of the free software office package, this allowed the collection of data, which contributed to the analysis related to the study topic.

Likewise, the secondary schools were visited to collect information on the population of students and teachers of each one of them.

$n=\frac{N \sigma^{2} Z^{2}}{(N-1)_{e}^{2}+\sigma^{2} Z^{2}}$

The formula shown above was applied, which showed that 135 students and 44 teachers from the total population of the secondary schools in the town had to be interviewed. Where $\mathrm{n}$ is equal to the sample size, $\mathrm{z}$ is the confidence level, which was determined to be $95 \%, \mathrm{~N}$ equals the number of people that make up the population to be studied (135 students and 44 teachers); $\circ$ corresponds to the desired sample error, which is $5 \%$.

Then, 57 students from the Manuel F. Montoya secondary school, 55 from the Technical 24 secondary school and 23 from the Salvatierra School were selected. As for the teachers, 20 from the Manuel F. Montoya secondary school were selected, 17 from the Technical 24 secondary school and 7 of the Salvatierra College, to carry out the surveys and questionnaire, in order to obtain corresponding data and proceed to the analysis of the information, which were revealing data.

Once the instruments for data collection have been applied, the results obtained through the designed instruments will be presented, in order to determine relevant information about the different environments that exist in each of the aforementioned schools. Each instrument will be submitted to the evaluation, from the methodological point of view, in order to validate the applied tools, allowing to have a greater knowledge regarding the software installed in each of the secondary schools. 
On the other hand, it should be mentioned that most of the secondary schools have Microsoft Office parcel installed in their computer laboratories, however, by implementing this tool they will benefit from familiarizing themselves with new software without having to pay for a license, giving guideline to new knowledge in the field of computing.

In addition, by obtaining this data, this same procedure can be replicated in all secondary schools in the country, as a new alternative to develop their work under a free license.

\section{Results}

\section{Secondary office automation parcel}

Office packages are computer programs that are used to automate office activities, such as writing letters, generating reports, processing data; The importance of these programs in education is that they are of great help for the academic development of students, because they are an instrument for carrying out school work with better presentation and formality, and they also promote quality in the work that students present, through the wide range of tools they have, it should be mentioned, in secondary schools is where students have the first contact with subjects focused on computing, therefore, is where they begin to familiarize themselves with the package of Office automation, throughout the country the office automation package used for education is the already known worldwide Microsoft Office, this is because most of the people automatically relate office automation to the one already mentioned above, this being the best known by both teachers and students of this educational level considering it the easiest to use, while the different alternatives Existing pathways are being wasted for the educational field.

The author (Stallman R., 2016) argues that schools have a social mission to educate and teach students to be capable and independent of megacorporations, something that schools are not fulfilling, because they are only limited to the use of Microsoft Office, however, they forget to promote the use of free software, which provokes and increases the students' lack of knowledge about other office software alternatives, such as free software.
A study was carried out in the secondary schools in the town of Santa Rosalía (Manuel F. Montoya, Colegio Salvatierra and Técnica 24) to find out the office package they use.

What office packages do you use?

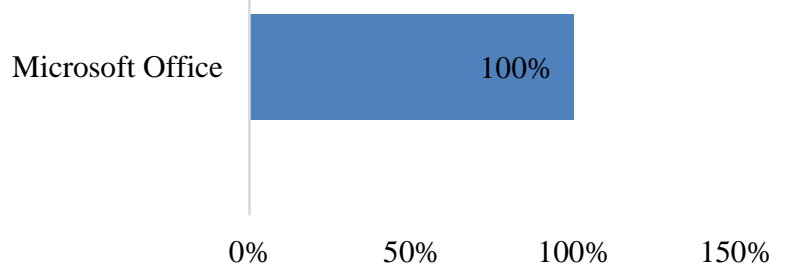

Graphic 1 Office equipment parcels used in the secondary schools of Santa Rosalía Baja California Sur

Source: own elaboration; Taken from the study "Use of Free Software Office Package in Secondary Schools of Santa Rosalía Baja California Sur"

According to the results obtained from the study carried out on secondary school teachers and students, as shown in Graphic 1, it was obtained as a result that the three institutions surveyed in their entirety use the Microsoft Office office software package.

This causes secondary school students and teachers to be unaware of other office software packages such as free software, which would provide benefits for the institution in terms of economics and for students because it helps to develop skills and knowledge that with software You cannot own it, as alternatives there are free software packages that have an interface similar to Microsoft Office, such as LibreOffice, which is considered optimal to carry out the migration to free software without causing a drastic change that has an impact on the academic development of students or the planning of teachers, because the adaptation time to this new package is considered short, given that it has a friendly and intuitive interface for all types of users. 


\section{Most used office software packages}

The office package consists of programs that help to systematize tasks carried out within an office, which are: Word processors, spreadsheets, presentation tools, page layout and layout, and database manager, however, these programs help students to carry out academic work with greater professionalism and formality, which allows teachers to prepare and maintain control over their classes, in addition to organizing the materials to be used within them, despite the use of office software vary depending on the user.

From the authors' point of view (Rubio \& Callejón Picón, 2014) the office package is made up of programs, such as: word processors (to write documents), spreadsheets (to perform mathematical operations), presentations ( to help transmit ideas in an audiovisual way), databases (to process and store information), these programs allow information to be processed automatically by means of computers, helping to reduce the time it takes to carry out activities within the office and educational environment. It can be seen in Graphic 2 that the most widely used software package for office automation by teachers in secondary education is the word processor with $77 \%$, followed by presentations with $16 \%$ and spreadsheets with $7 \%$.

\section{Ofimaticas Programs most used by} teachers?

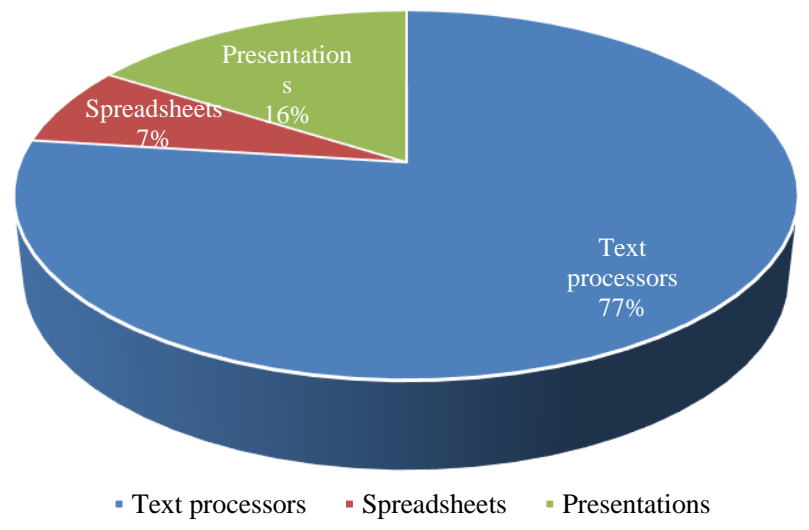

Graphic 2 Programs used by teachers in local high schools

Source: own elaboration; Taken from the study "Use of Free Software Office Package in Secondary Schools of Santa Rosalía Baja California Sur"
On the other hand, Graphic 3 shows that the most used software package for office automation by high school students is the word processor with $77 \%$, the presentations are with $20 \%$ use and the spreadsheets with $3 \%$.

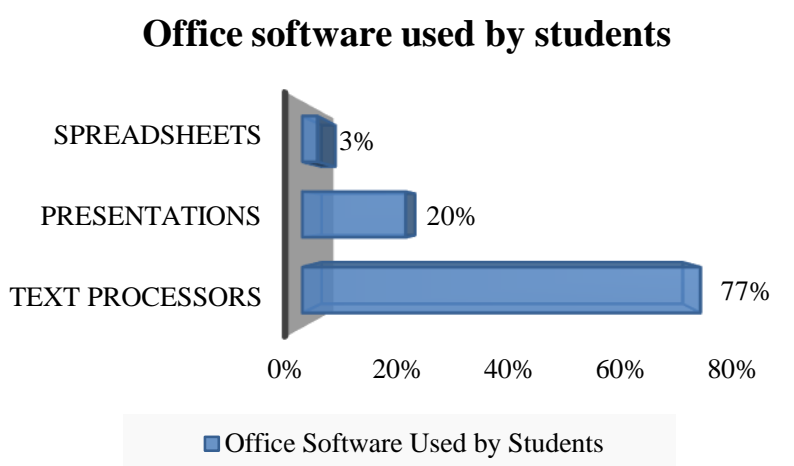

Graphic 3 Programs used by students in the local high schools

Source: own elaboration; Taken from the study "Use of Free Software Office Package in Secondary Schools of Santa Rosalía Baja California Sur"

According to the figures shown, it can be seen that both students and teachers use word processors more frequently, both coinciding with $77 \%$, and it can also be seen that they also coincide in the use of presentations and spreadsheets, however, the percentage of the latter differs, it can be seen that teachers have a higher percentage in the use of spreadsheets with $7 \%$, while students $3 \%$ in the use of the same, on the other On the other hand, the use of presentations is higher in students, obtaining $20 \%$ as a result, while teachers with $16 \%$.

It is important to mention that the percentages obtained on the use of office automation package programs are low for both students and teachers, both mentioned the lack of knowledge for handling these tools, missing out on the development opportunities they provide for education. and better performance for teachers, it is important to note that the lack of knowledge and use of office automation package programs by the teacher causes an increase in ignorance of these tools in students at the basic educational level, which means that this situation keep crawling to higher education levels. 


\section{Places where the office package is used}

Office software is designed to be used by all types of users, whether or not they have extensive experience in the use of computer equipment, as well as being a de facto standard since they are suitable for any type of organization, due to which they can Being used in different areas of daily life, therefore, it is important that from basic education levels such as high school, students are taught to use these tools as part of academic development, which will help them to develop more Ease in higher education levels and the labor field, although it is in schools that they begin to use office automation programs, this is not the only place where they are used and you learn to use them.

As noted, (Corrales, Computer Technical Assistant, 2012) the scope of office automation tools is very broad since the programs that make it up fulfill functions that facilitate the processing and safeguarding of different types of information.

Graphic 4 shows the places where teachers use office automation packages, being at work where they use it the most with $80 \%$, in leisure time $18 \%$ and with $2 \%$ in other places such as internet cafe, at home, among others.

Regarding the results of the students, Figure 5 illustrates that the place where they use the office parcel the most is the school with $42 \%$, in their free time with $21 \%$ and finally, in the workplace $37 \%$.

\section{Places where the office package is used} (Students)

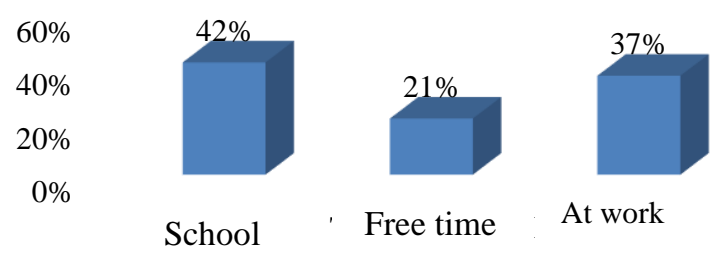

Graphic 4 Places where office automation packages are used by students

Source: own elaboration; Taken from the study "Use of Free Software Office Package in Secondary Schools of Santa Rosalía Baja California Sur"
During the study, the teachers mentioned that the office equipment package is also used in their homes during their free time to carry out activities related to their work, the same happens with the students, because in their free time they use it to do In spite of this, academic works both miss out on a large part of the functionalities of these office programs, the main cause of this problem being the lack of knowledge to handle them, which causes inefficiency in the other areas where these same programs are used.

\section{Knowledge of free software package in secondary schools}

As mentioned above, a large number of secondary school students and teachers lack the knowledge to use office automation programs properly, but what if they both knew how to use it correctly? They would have the possibility to take advantage of all the advantages they offer, for teachers it would decrease the time of carrying out activities related to their work, as far as the students would be facilitated the use of these to carry out school work, these advantages would be favorable for the academic development of students and in the same way for the professional development of teachers, but what would happen if, in addition to knowing how to correctly use the office automation package they currently use (Microsoft Office), they knew other alternatives? They would have the opportunity to choose the package that suits the needs of the activity they want to carry out and, in this way, many limitations to which e They face. For this reason (Stallman R., 2016) points out that implementing the use of free software in schools is much more than a way to improve education a little, it is more about replacing a bad education with a good one offering new growth opportunities. and development.

With respect to the data obtained, Graphic 5 shows the percentage of knowledge of free software office package by teachers, with $89 \%$ being unaware, and $11 \%$ being aware of it. 


\section{Knowledge of the Free Software Office package in secondary schools (Teachers)}

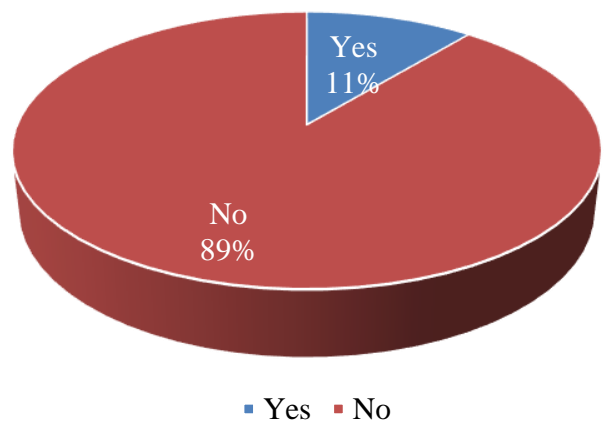

Graphic 5 Knowledge of the free software office package by teachers

Source: own elaboration; Taken from the study "Use of Free Software Office Package in Secondary Schools of Santa Rosalía Baja California Sur"

Likewise, the results obtained by the students illustrate in Graphic 6 that $94 \%$ do not know the free software office package and $6 \%$ do.

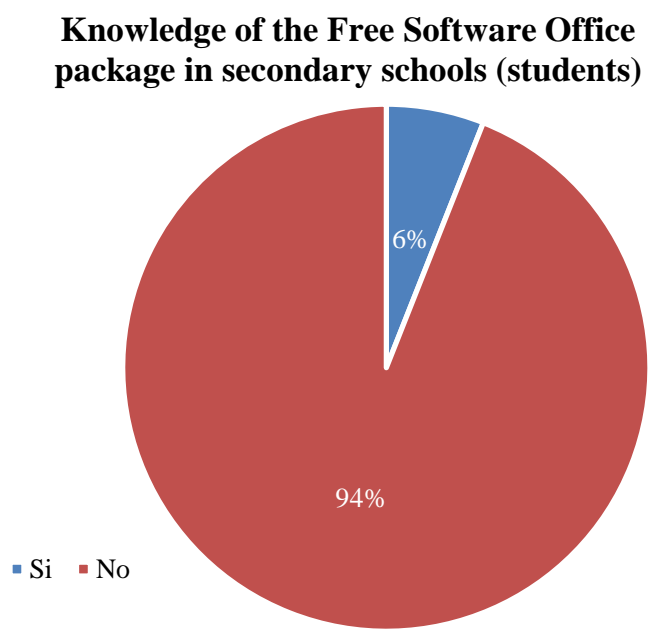

Graphic 6 Knowledge of the free software office package by students

Source: own elaboration; Taken from the study "Use of Free Software Office Package in Secondary Schools of Santa Rosalía Baja California Sur"
Within this context it can be pointed out that a high percentage of students and teachers are unaware of the existence of the free software office package, on the other hand, those who answered that if they know of the existence of this, most of them are students and teachers who They are related to computer matters, however they mentioned that they do not know how to use them, this high level of ignorance causes the loss of opportunities that these packages offer, and in the same way generates that schools train students enslaved to the use of proprietary software which becomes in a bigger problem at the time of these becoming professionals, carrying with them the same problem mentioned above.

\section{Interest in learning how to use free software office packages}

The free software package turns out to be an unknown topic for students and teachers at the basic educational level, however, it is not an impediment for students and teachers to want to learn, many of the respondents showed interest in this package, they also showed the results on the knowledge of this parcel within the secondary schools, where I highlight the lack of knowledge of the existence of these, which makes clear the insufficiency of alternatives they have to carry out their activities, although the interest in part of students and teachers of these institutions to know and learn to use new office software package tools, it is essential to start and carry out the migration to free software office software package, bringing benefits for both parties.

Abounding about it (Burgos, 2012) points out that migrating to a free software-based application is no different than another type of application; Since the same steps for adoption, only prior knowledge is required.

Due to this, the importance of the teacher learning to correctly handle the functionalities of the free software office programs to which they are going to migrate arises.

It can be seen in Graphic 7 it refers to the interest shown by teachers to learn how to use the free software office package, showing that 97\% are interested in learning, while 3\% are not interested. 


\section{Interest in learning to use Office package (Teachers)}

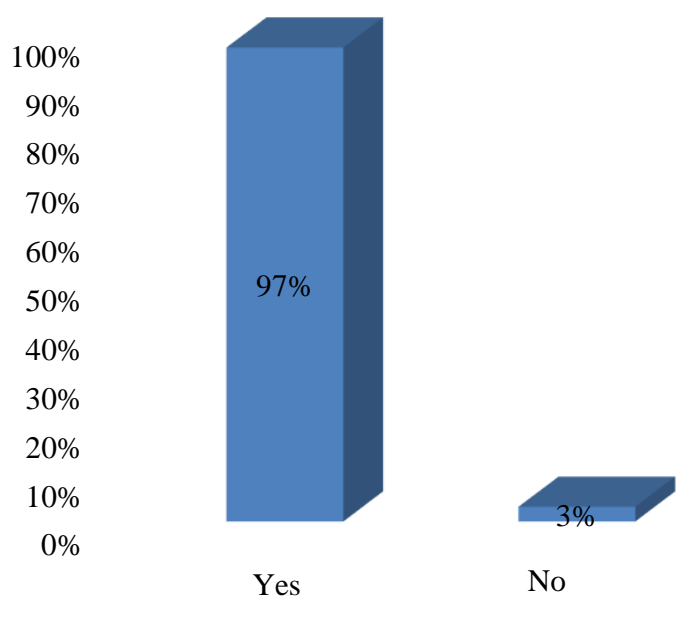

Graphic 7 Interest in learning how to use the free software office package by teachers

Source: own elaboration; Taken from the study "Use of Free Software Office Package in Secondary Schools of Santa Rosalía Baja California Sur"

On the other hand, Graphic 8 shows the percentage of students who are interested in learning how to use the free software office package, with Technical high school students with $44 \%$ showing the most interest, followed by Manuel F. Montoya with $42 \%$ and in last place the Colegio Salvatierra with $14 \%$.

\section{Interests of learning to use free software office package students}

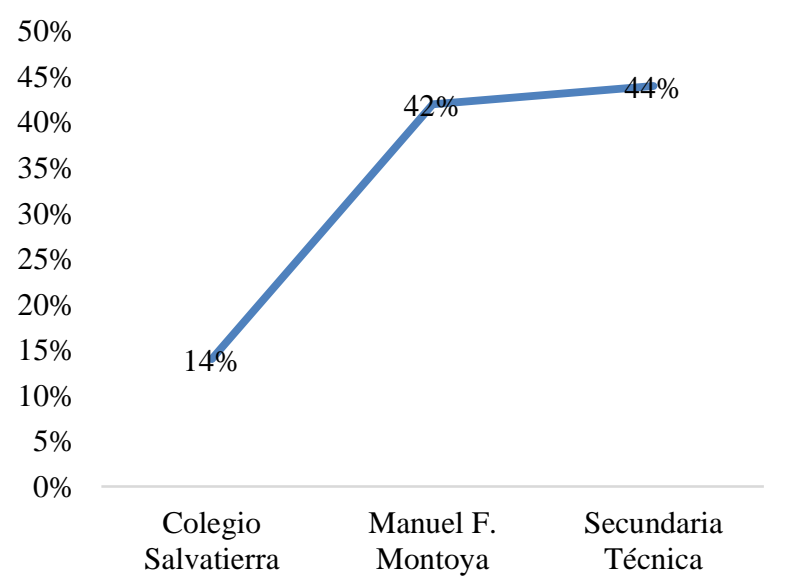

Graphic 8 Interest in learning how to use the free software office package by students

Source: own elaboration; Taken from the study "Use of Free Software Office Package in Secondary Schools of Santa Rosalía Baja California Sur"
The evidences shown highlight the large percentage of students and teachers willing to learn to use the free software office package, which shows the desire to acquire new knowledge and skills, this makes it even easier to carry out the migration to this new alternative, for this reason, it must be taken into account by the corresponding authorities of each secondary school to take advantage of this opportunity, since by implementing this new package it will allow them to learn more office automation tools, therefore it brings benefits for the students and teachers involved.

\section{Willingness to learn to use free office automation.}

To begin the migration to the free software office package within the secondary schools of the town, it is essential to know the availability of the students and teachers, since it will depend on whether said migration is successful when implementing it, it is known that it always exists resistance to change, due to the fact that its magnitude or adaptation time is unknown, however, it should be noted that having various alternatives will contribute to the development of both, strengthening their skills and knowledge, because of this, the opportunity presents by having students and teachers willing to learn how to use this free software package.

As stated (Suárez, 2013) to migrate to free software, it is not enough to change the applications on the users' computers, but the way of working with these tools must also be modified, adapting them to their needs.

In addition to this, Graphic 9 shows the number of hours that teachers are willing to invest during their free time to learn how to use the free software office package, obtaining the highest percentage of 2 hours a day with $34 \%, 3$ hours a day with $30 \%, 1$ hour a day $22 \%$ and less than an hour with $14 \%$. 


\section{Willingness to learn Free software office teachers}

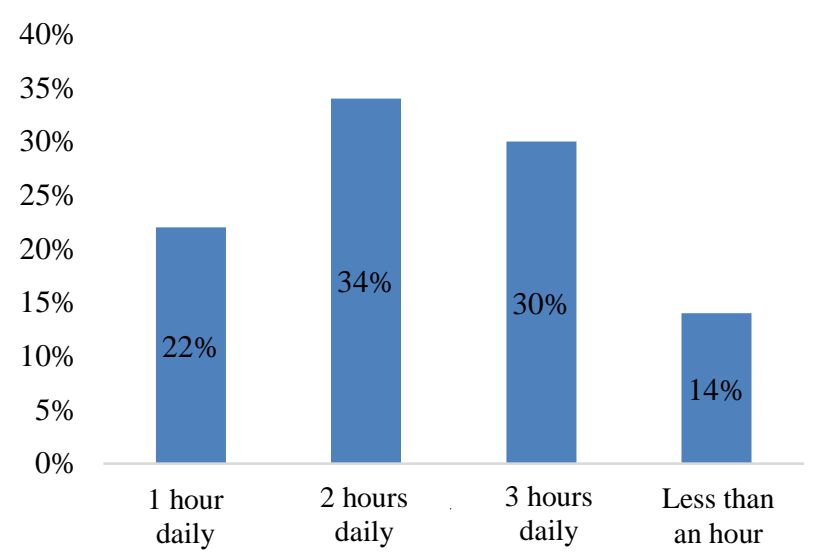

Graphic 9 Willingness to learn the free software office package by teachers

Source: own elaboration; Taken from the study "Use of Free Software Office Package in Secondary Schools of Santa Rosalía Baja California Sur"

According to the study, Graphic 10 reveals the willingness of students to learn to use this package, with 1 hour per day being the amount of time invested that obtained the highest percentage with $47 \%$, followed by 2 hours per day with $31 \%$, less one hour with $15 \%$, finally, 3 hours a day with $7 \%$.

\section{Willingness to learn Free Software office automation, students}

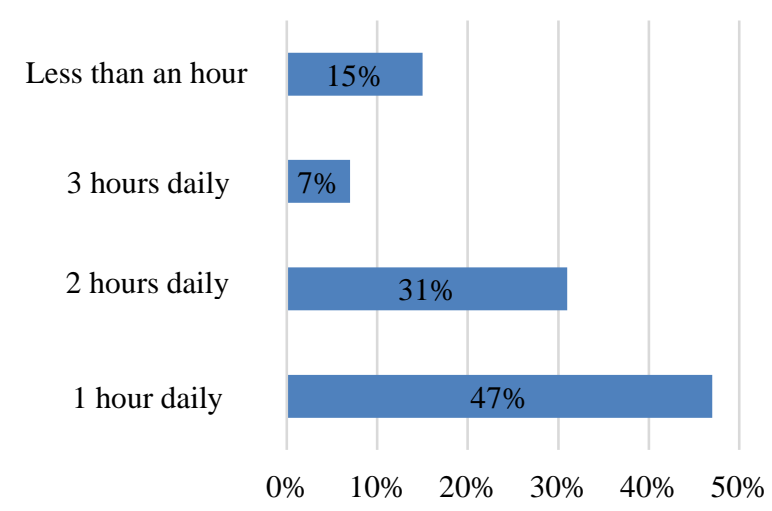

Graphic 10 Willingness to learn the free software office package by students

Source: own elaboration; Taken from the study "Use of Free Software Office Package in Secondary Schools of Santa Rosalía Baja California Sur"

Within this framework, it can be seen that a favorable response was obtained from both parties (students and teachers), showing the best disposition to learn to use this new tool based on free software, where it was possible to perceive the desire to learn and improve its use.
Of office automation parcels, regarding this, the students commented that they would like to be taught within the same secondary school to use this parcel, since they are more facilitated if teachers guide them during learning, while teachers suggest that they are given a training course to learn how to use it and make the most of its features and to share the knowledge acquired.

\section{Results}

Libre office (free software package) as an alternative to microsoft office

To carry out the migration to the free software office package, it was determined that the optimal option to be implemented in education at the basic level (secondary) is the LibreOffice package, because it has a similar interface and functions to which is already used (Microsoft Office), with this the students and teachers will not feel a drastic change, thus being faster the adaptation, in addition to having constant updates and improvements to maintain its easy use and friendly interface for all kinds of users.

During the study carried out, the LibreOffice office package was installed in some computers in secondary schools, with the objective of showing the operation and interface of this one to teachers and students, later they were asked to use it and make their opinion known about this. Given this situation, Graphic 11 shows the percentage of teachers who consider LibreOffice packaging as an alternative, with $91 \%$ considering it and being willing to use it and 9\% not interested in it.

\section{Consider the LibreOffice package as an alternative, teachers}

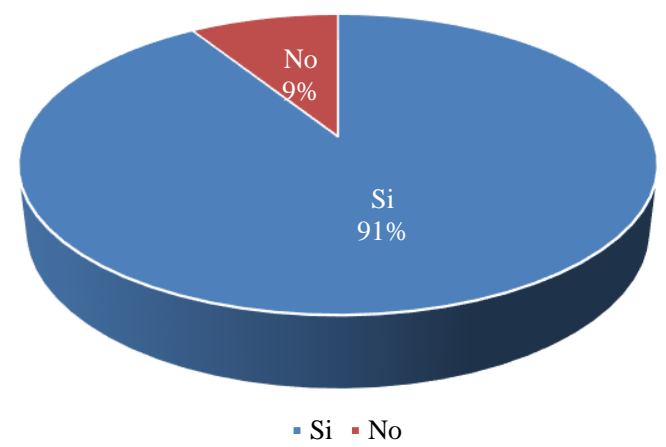

Graphic 11 LibreOffice office package as an alternative (Teachers)

Source: own elaboration; Taken from the study "Use of Free Software Office Package in Secondary Schools of Santa Rosalía Baja California Sur" 
Similarly, Graphic 12 shows that $89 \%$ of students consider LibreOffice as an alternative, while $11 \%$ do not consider it and are not interested in learning how to use it.

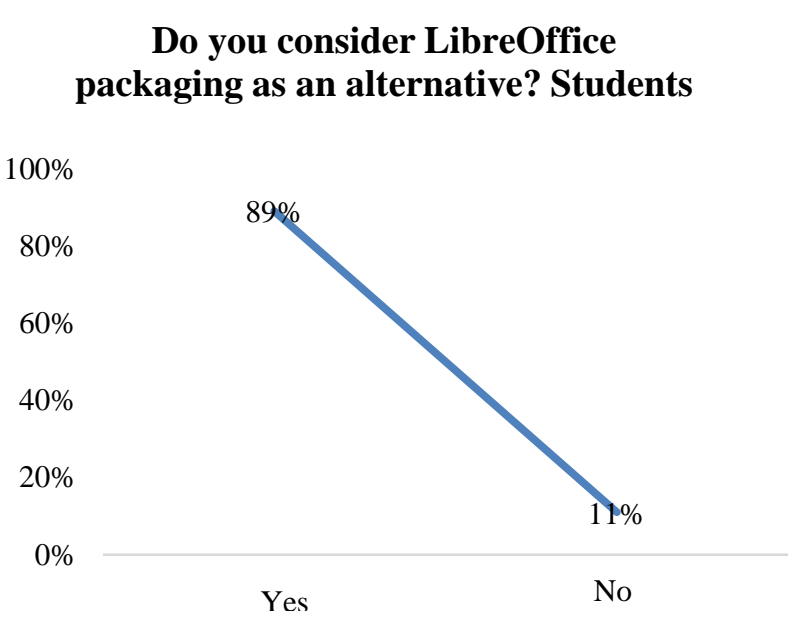

Graphic 12 LibreOffice office package as an alternative (Students)

Source: own elaboration; Taken from the study "Use of Free Software Office Package in Secondary Schools of Santa Rosalía Baja California Sur"

On the basis of the results presented, it highlights that a high percentage of students and teachers consider LibreOffice as an alternative and mentioned that, if they learn to use it and exploit the functions it has, they could migrate to this package based on free software, it is worth mentioning that enthusiasm and availability was shown by students and teachers, upon learning of the existence of this parcel, which was unknown to them, these data cannot be ignored by the corresponding authorities, since it is a wake-up call that encourages them to take the necessary measures to improve aspects in the education of students and the performance of their teachers, which together will contribute to the academic strengthening of the institution.

\section{Conclusions}

Thanks to the availability of the directors of the local high schools, who gave the opportunity to carry out the study, where a favorable response was obtained regarding the acceptance of the package based on free software (LibreOffice), according to the results obtained, it is hoped that the implementation of this office package in basic education will improve the quality of teaching within the institutions that use it, training students capable of developing in different areas and higher educational levels, due to the fact that a high enthusiasm from both parties to invest time and effort to learn to use this tool and to be able to take full advantage of the benefits that it provides for teaching, in addition to providing new tools where the cost of use is relatively low, thus helping the economy of the institutions.

\section{References}

Burgos, R. H. (2012). Implementación de aplicaciones Informáticas basadas en software libre en bibliotecas y unidades de información. e-Ciencias de la información, 13.

Corrales, J. D. (2012). Ayudante técnico de informática. España: MAD-Eduforma.

Rubio, J. M., \& Callejón Picón, F. (2014). Tecnologias de la Información y la Comunicación. España: Planeta Alvi.

Stallman, R. (18 de 11 de 2016). Free Software Foundation. Obtenido de Free Software Foundation:

https://www.gnu.org/education/eduschools.es.html

Suárez, J. D. (2013). Factores críticos de éxito para la migración de la ofimática al software libre. Universidad Simón Bolivar, 170. 